\title{
Interspace between the Popliteal Artery and the Capsule of the Knee (IPACK) Block for Anterior Cruciate Ligament Reconstruction Surgery: A Two Case Series
}

\author{
Agnes Huang, Prit Anand Singh, Kwee Lian Woon \\ Department of Anesthesia and Surgical Intensive Care, Changi General Hospital, Singapore \\ Email: agnes.huang.w.w@singhealth.com.sg
}

How to cite this paper: Huang, A., Singh, P.A. and Woon, K.L. (2020) Interspace between the Popliteal Artery and the Capsule of the Knee (IPACK) Block for Anterior Cruciate Ligament Reconstruction Surgery: A Two Case Series. Open Journal of Anesthesiology, 10, 134-143.

https://doi.org/10.4236/ojanes.2020.104012

Received: March 13, 2020

Accepted: April 18, 2020

Published: April 21, 2020

Copyright $\odot 2020$ by author(s) and Scientific Research Publishing Inc. This work is licensed under the Creative Commons Attribution International License (CC BY 4.0).

http://creativecommons.org/licenses/by/4.0/

\begin{abstract}
This case series describes the use of Interspace between the Popliteal Artery and the Capsule of the Knee (IPACK) block to provide motor-sparing analgesia for two consecutive patients undergoing anterior cruciate ligament reconstruction (ACLR) by the same surgeon. Case 1 demonstrates the use of a proximal IPACK block as a post-operative rescue block for a patient who still experienced severe pain despite having received a femoral nerve block and parenteral opioids. Case 2 describes the use of a modified IPACK block as part of a multimodal approach with opioid and motor sparing effects. In both cases, the IPACK block provided satisfactory pain relief in the immediate postoperative period without motor weakness, making it an effective analgesic method for day surgery. With the IPACK block shown to be an effective nerve block for ACLR, we explore other advantages, limitations and further research required to better define the role of this block.
\end{abstract}

\section{Keywords}

IPACK, Anterior Cruciate Ligament Reconstruction

\section{Introduction}

Anterior cruciate ligament reconstruction (ACLR) surgery is associated with moderate to severe postoperative pain which can be attributed to both arthroscopic surgery and the graft donor site [1]. A multimodal analgesia regime with peripheral nerve blocks (PNB) is therefore recommended for this procedure [2]. There are various choices of PNBs available either as a single injection or in combination. Given the multiple innervations of the knee, complete pain relief 
would not be expected from either the femoral nerve block (FNB) or the saphenous nerve block [3] [4] alone.

The recent technique of ultrasound guided local anesthetic infiltration of the interspace between the popliteal artery and the capsule of posterior knee (IPACK) has shown promising results [3] [5] [6]. The technique involves a very selective block of the terminal sensory branches of the posterior aspect of the knee without the involvement of motor branches of the tibial and peroneal nerves leading to reduced pain without motor weakness [7] [8]. This leads to earlier ambulation, rehabilitation and recovery in various knee surgeries [6].

The IPACK block has evolved from being performed in a prone position where the injection occurs at the popliteal crease at the level of the femoral condyles, to being done with the patient supine. In the supine position, the transducer is placed in the medial lower third aspect of the thigh to observe the femoral artery under the sartorius muscle. The transducer is then slid caudally to trace the artery as it dives into the popliteal fossa through the adductor hiatus to become the popliteal artery [3] [7] [8] [9] [10]. We aim to block the popliteal plexus, saphenous nerve and nerve to vastus medialis with a single injection by redirecting the needle after a single puncture. This avoids multiple injections sites.

We describe our experience with the proximal approach of the IPACK block for ACLR.

These 2 patients were selected as they were under the care of the same surgeon and anesthetist. The IPACK block was offered to reduce pain, opioid consumption and facilitate early rehabilitation and discharge.

\section{Case Presentation}

Written informed consent was provided by all patients for inclusion in this report.

\subsection{Case 1}

We present a 29 year old ASA physical status 1 male $(186 \mathrm{~cm}, 110 \mathrm{Kg}$, BMI 32), with allergy to non-steroidal anti-inflammatory drugs, who underwent a left knee ACLR with hamstring autograft, medial meniscus repair and extra-articular tenodesis. He received oral paracetamol $1 \mathrm{~g}$ one hour prior to surgery for preemptive analgesia. A femoral nerve block was performed preoperatively under ultrasound guidance with $15 \mathrm{ml}$ of $0.5 \%$ Ropivacaine as per our hospital pathway. He received a general anesthetic (GA) with a supraglottic airway for the surgery. GA was maintained with nitrous oxide and desflurane. Intraoperative analgesia comprised of fentanyl $100 \mathrm{mcg}$, ketamine $50 \mathrm{mg}$ and oxycodone $10 \mathrm{mg}$. Surgery duration was 80 minutes. The patient had a pain score of 7/10 over the posterior knee 1 hour after the end of surgery whilst in the post anesthesia care unit (PACU). The IPACK block was hence offered. As the knee was bandaged, we used the proximal approach to avoid the surgical dressing. Under ultrasound guidance using the curvilinear probe, we traced the femoral artery caudally beginning under the sartorius muscle to where it dives deep at the adductor hiatus. A $150 \mathrm{~mm} 21$ gauge needle (Stimuplex, B. Braun) was inserted in an anteromedial-posterolateral di- 
rection to the space between the popliteal artery and the femoral shaft. The needle was advanced $1-2 \mathrm{~cm}$ lateral to the popliteal artery in close proximity to the femoral shaft. After negative aspiration, $25 \mathrm{ml}$ of $0.5 \%$ Ropivacaine was injected as the needle was gradually withdrawn. Ultrasound scan confirmed that the local anesthetic agent did not spread to the sciatic nerve (Figure 1). His pain score decreased to $0 / 10$ within 5 minutes of the block. Plantar flexion and extension of bilateral feet were tested to be equal and full.

\subsection{Case 2}

A 25 year old ASA physical status 1 male ( $173 \mathrm{~cm}, 73 \mathrm{~kg}$, BMI 24) who underwent a left knee ACLR with hamstring autograft and lateral meniscus repair. $\mathrm{He}$ received oral paracetamol $1 \mathrm{~g}$ and etoricoxib $120 \mathrm{mg} 1$ hour prior to surgery for preemptive analgesia. He was offered a modified IPACK block and adductor canal block which were performed pre-operatively. The patient was placed in a supine position with the left leg externally rotated and flexed (Figure 2). The proximal IPACK block was performed as described above with $15 \mathrm{ml}$ of $0.5 \%$ Ropivacaine given as the needle was withdrawn (Figure 3(a)). The needle is then redirected to deposit $10 \mathrm{mls}$ of Ropivacaine under the Sartorius muscle (Figure 3(b)). General Anaesthesia with a supraglottic airway device was then induced and maintained with nitrous oxide and desflurane. Intraoperative analgesia consisted of fentanyl $100 \mathrm{mcg}$ and ketamine $25 \mathrm{mg}$. Surgery duration was 50 minutes. Immediate post-operative pain scores were $0 / 10$ at rest and $1 / 10$ on movement. He did not require any opioids in the post-operative period. Patient was able to elevate his operated leg and perform plantar and dorsiflexion in the post anesthesia care unit (Table 1).

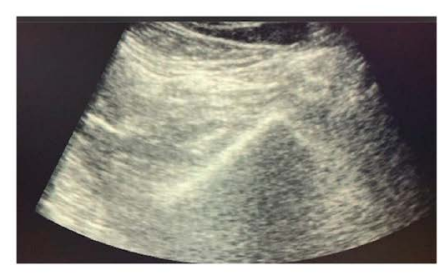

Pre injection image

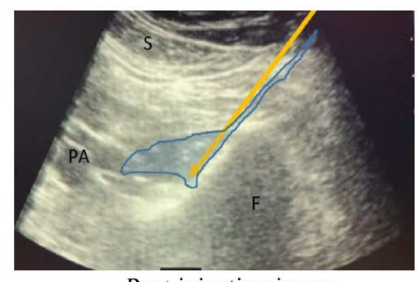

Post injection image

Figure 1. Ultrasound scan of IPACK block with spread of local anaesthetic. $S=$ Sartorius muscle, $\mathrm{F}=$ Femoral shaft, $\mathrm{PA}=$ Popliteal artery.

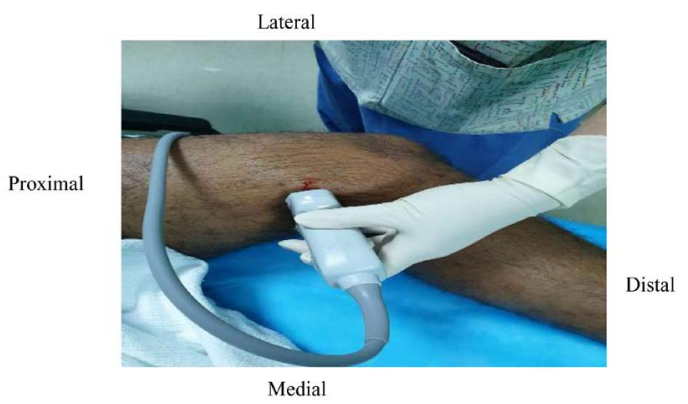

Figure 2. Patient position of the left leg with slight external rotation and knee flexion and ultrasound probe placement during IPACK block. 


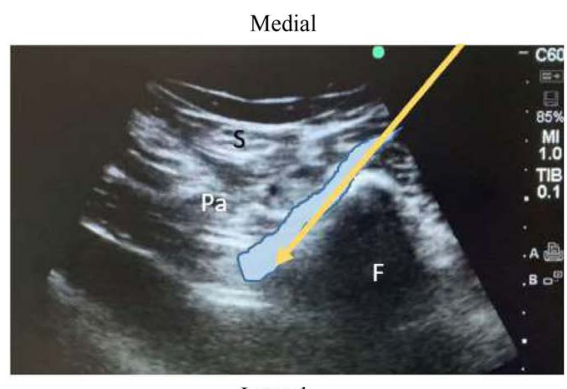

Lateral

(a)

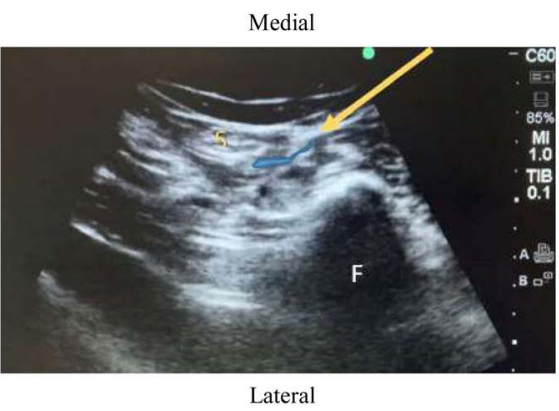

(b)

Figure 3. $\mathrm{F}=$ Femur, $\mathrm{S}=$ Sartorius muscle, $\mathrm{Pa}=$ Popliteal artery. Arrows indicate direction of needle with LA (blue area) deposits.

Table 1. Summarizes the patient characteristics of the 2 patients.

\begin{tabular}{|c|c|c|}
\hline & Case 1 & Case 2 \\
\hline Age (years) & 29 & 25 \\
\hline Gender & Male & Male \\
\hline Race & Chinese & Chinese \\
\hline BMI & 32 & 24 \\
\hline ASA Physical Status & 1 & 1 \\
\hline Anesthesia Technique & GA with LMA & GA with LMA \\
\hline Surgery Duration (min) & 80 & 50 \\
\hline Pre emptive analgesia & Paracetamol $1 \mathrm{~g}$ & $\begin{array}{l}\text { Paracetamol } 1 \mathrm{~g} \\
\text { Etoricoxib } 120 \mathrm{mg}\end{array}$ \\
\hline Intra operative Analgesia used & $\begin{array}{l}\text { Fentanyl } 100 \mathrm{mcg} \\
\text { Oxycodone } 10 \mathrm{mg} \\
\text { Ketamine } 25 \mathrm{mg}\end{array}$ & $\begin{array}{l}\text { Fentanyl } 100 \mathrm{mcg} \\
\text { Ketamine } 25 \mathrm{mg}\end{array}$ \\
\hline Nerve block performed preoperatively & Femoral Nerve block & $\begin{array}{l}\text { Modified IPACK block } \\
\text { and adductor canal block }\end{array}$ \\
\hline IPACK Block performed & $\begin{array}{l}\text { Rescue block } 1 \mathrm{~h} \\
\text { post operatively }\end{array}$ & $\begin{array}{l}\text { Preemptive analgesia } \\
\text { done preoperatively }\end{array}$ \\
\hline \multicolumn{3}{|l|}{ Pain score 1 hour post op } \\
\hline - $\quad$ At rest & 7 & 0 \\
\hline - on movement & 10 & 1 \\
\hline - $\quad 5$ min after rescue block & 0 & - \\
\hline Complications & Nil & Nil \\
\hline
\end{tabular}

\section{Discussion}

Multimodal analgesia consisting of two or more modalities is recommended for ACL reconstruction surgeries to reduce opioid consumption and shorten hospital stay [11] [12] [13] [14]. A repertoire of regional anesthesia options includes epidural [15], lumbar plexus block [16] [17], psoas compartment block [18], femoral nerve block (FNB) [19], adductor canal block [20] and sciatic nerve block [16] [21] [22]. More recently, addition of the obturator nerve block to the ad- 
ductor canal block has been recommended [23]. There have been systematic reviews for Local Infiltration techniques [24]. Regional techniques have evolved from the more invasive central neuraxial and deep compartment blocks to equally effective peripheral techniques with reduced risks and motor blockade. Whilst some of the peripheral nerve blocks are less risky and easier to perform, a combination of two or three blocks [16] [25] may be needed to provide complete analgesia for the knee making them uncomfortable for the patient. Potential motor blockade makes these combination PNBs unsuitable for day surgery.

There has been a move towards finding a more suitable analgesic option that does not impair motor function such as local infiltration of analgesia (LIA) by surgeons, as first described by Kerr [26]. However, the infiltration is performed blind by the surgeon into the posterior capsule and risks blocking the sciatic and common peroneal nerve (Figure 4). There is a wide variation in content, volume and sites performed by the surgeon with thus variable analgesic effect.

IPACK block is an alternative to provide analgesia to the posterior aspect of the knee with less risk of motor blockade. This is accomplished by blocking the articular branches of the obturator, common peroneal (CPN) and tibial nerves within the popliteal fossa [3] [7] [8]. As this technique is performed under ultrasound guidance, the possibility of blocking the sciatic nerve or CPN is reduced. Table 2 summarizes the advantages and disadvantages of the IPACK block in comparison with other commonly performed blocks.

There have been cadaveric studies to observe the spread of dye with various approaches and differing volumes [7] [8] [10] to understand the potential nerves blocked in the IPACK block. The ideal level and volume of injectate has yet to be determined. There are postulations that the popliteal plexus (end articular nerves) may be blocked with $15 \mathrm{mls}$ of local anaesthesia given in the caudal end of the adductor canal [8] [25]. The dye is shown in cadaveric studies to spread via the adductor hiatus into the popliteal region [8]. A single injection at the distal adductor canal may be able to block both the saphenous nerve and the popliteal plexus within the popliteal fossa. Clinical studies will need to be conducted to determine the ideal approach, volume and if combination with other PNBs has added analgesic benefit [10] [11] [25].

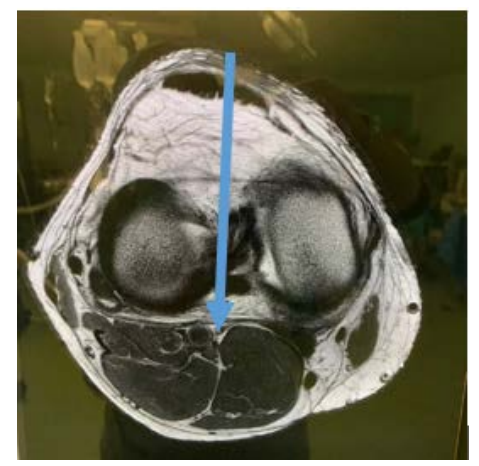

Figure 4. MRI image cross section of knee showing the lose proximity of the neurovascular bundle to the posterior capsule. Arrow indicates direction of LIA. 
Table 2. Comparison of the IPACK block and other commonly performed blocks.

\begin{tabular}{|c|c|c|c|c|c|}
\hline & IPACK & LIA & Femoral Nerve Block & Adductor Canal block & Sciatic Nerve Block \\
\hline $\begin{array}{l}\text { Usual volume } \\
\text { of LA (mls) }\end{array}$ & 15 & 150 & $10-15$ & $10-20$ & $10-25$ \\
\hline Nerves covered & $\begin{array}{l}\text { Terminal sensory branches } \\
\text { of obturator, CPN and } \\
\text { tibial nerves }\end{array}$ & $\begin{array}{l}\text { Local \& systemic } \\
\text { effects }\end{array}$ & Femoral nerve & Saphenous nerve & $\begin{array}{l}\text { Posterior Tibial } \\
\text { nerve at } \\
\text { popliteal fossa }\end{array}$ \\
\hline \multirow[t]{2}{*}{ Advantages } & \multicolumn{5}{|c|}{ Safer blocks than central neuraxial blocks especially in patients with coagulopathy or patients on antiplatelet agents. } \\
\hline & $\begin{array}{l}\text { 1) Localised to periarticular } \\
\text { region with sparing of vastus } \\
\text { muscles; } \\
\text { 2) Minimal weakness thus } \\
\text { facilitates early rehabilitation; } \\
\text { 3) Relatively easy to perform } \\
\text { with lower risk of nerve injury; } \\
\text { 4) Potential of covering } \\
\text { saphenous nerve. }\end{array}$ & $\begin{array}{l}\text { 1) Performed by } \\
\text { surgeon and thus } \\
\text { less concern of } \\
\text { graft infection; } \\
\text { 2) Studies have } \\
\text { shown that it works } \\
\text { as well as Femoral } \\
\text { nerve block; } \\
\text { 3) Do not require } \\
\text { additional } \\
\text { ultrasound } \\
\text { machine/trained } \\
\text { anaesthetist. }\end{array}$ & $\begin{array}{l}\text { 1) Simple and } \\
\text { superficial block } \\
\text { that can be } \\
\text { performed by } \\
\text { most anaesthetist; } \\
\text { 2) Proven to have } \\
\text { opioid sparing and } \\
\text { pain scores in knee } \\
\text { procedures [2]. }\end{array}$ & $\begin{array}{l}\text { 1) Simple and } \\
\text { superficial block } \\
\text { that can be } \\
\text { performed by most } \\
\text { anaesthetists; } \\
\text { 2) Avoids blockade } \\
\text { of the vastus } \\
\text { lateralis and vastus } \\
\text { intermedius with } \\
\text { less impairment } \\
\text { of hip flexion. }\end{array}$ & $\begin{array}{l}\text { 1) Definitive } \\
\text { coverage of the } \\
\text { posterior knee; } \\
\text { 2) Relatively } \\
\text { easy to perform. }\end{array}$ \\
\hline Disadvantages & $\begin{array}{l}\text { 1) Relatively deep block } \\
\text { compared to the other } \\
\text { peripheral nerve blocks; } \\
\text { 2) LA spread may affect } \\
\text { sciatic nerve with potential of } \\
\text { motor blockade; } \\
\text { 3) Performed near surgical } \\
\text { site hence risk of surgical } \\
\text { site contamination; } \\
\text { 4) New technique with few studies; } \\
\text { 5) Few anaesthetists performs } \\
\text { the technique; } \\
\text { 6) Ideal approach and volume } \\
\text { yet to be determined. }\end{array}$ & $\begin{array}{l}\text { 1) Large volume } \\
\text { required with risk } \\
\text { of LA toxicity; } \\
\text { 2) Variability in } \\
\text { technique, volume } \\
\text { and concoction by } \\
\text { various surgeons; } \\
\text { 3) Not pre-emptive } \\
\text { and hence risk of } \\
\text { wind up } \\
\text { phenomenon. }\end{array}$ & $\begin{array}{l}\text { 1) Results in motor } \\
\text { blockade with risk } \\
\text { of fall and delayed } \\
\text { rehabilitation; } \\
\text { 2) Has not been } \\
\text { found to be more } \\
\text { advantageous than } \\
\text { multimodal } \\
\text { analgesia [2]; } \\
\text { 3) Does not } \\
\text { cover posterior } \\
\text { aspect of the knee. }\end{array}$ & $\begin{array}{l}\text { 1) Blocked performed } \\
\text { at site of tourniquet } \\
\text { may increase the risk } \\
\text { of nerve injury } \\
\text { (direct pressure, LA } \\
\text { axonal toxicity and } \\
\text { needle penetration); } \\
\text { 2) May still block } \\
\text { the branches to the } \\
\text { Vastus medial is if } \\
\text { large volume is given; } \\
\text { 3) The Adductor } \\
\text { canal or sub Sartorius } \\
\text { definition is still } \\
\text { controversial. }\end{array}$ & $\begin{array}{l}\text { 1)Foot drop may } \\
\text { occur if the } \\
\text { common peroneal } \\
\text { nerve is blocked; } \\
\text { 2) May delay } \\
\text { rehabilitation and } \\
\text { discharge; } \\
\text { 3) Does not cover } \\
\text { anterior aspect of } \\
\text { the knee. }\end{array}$ \\
\hline
\end{tabular}

The second case may support this theory that the adductor canal and the popliteal area is connected. Tran et al found that the dye injected from a medial IPACK approach tracked into the adductor canal and Runge et al found that dye injected in the adductor canal tracks in the popliteal area [7] [8]. If the nerve to the vastus medialis can be blocked with this same injection, it would avoid having to do a second block at the femoral triangle [27] or adductor canal [6] [11]. In their feasibility study by Runge et al., their needle was directed from the vastus medialis toward the femoral artery as it exits the adductor hiatus with the local anaesthetic deposited near the artery [25]. In our second case, we directed our needle more proximally, under the sartorius muscle, similar to a sub-sartorial adductor canal approach. The patient had good analgesia and opioid sparing effect with no significant motor blockade. This would make the IPACK block an ideal preemptive analgesic technique for day surgery as it can be added to a non-opioid multimodal analgesia pathway [2]. 
However, the clinical analgesia provided by modification of this IPACK block needs further studies to determine the optimal volume and dose of local anesthetic at the various injection sites. The injection at the adductor canal may be preferred as it is further from the surgical site allowing for catheter placement and reduced risk of surgical site contamination.

\section{Conclusion}

Our case series demonstrates the use of proximal IPACK block for ACLR surgeries as a useful analgesic option which is safe, effective and easy to perform. There was also significant opioid sparing effect with reduced risk of motor blockade. As the IPACK block is still evolving, further randomized controlled studies are required to determine the optimal site, volume and dose of LA required to achieve the desired clinical results; and to assess the safety and efficacy of this technique against other blocks.

\section{Conflicts of Interest}

The authors declare no conflicts of interest regarding the publication of this paper.

\section{Consent for Publication}

Informed consent was obtained for all patients.

\section{Authors' Contribution}

KLW and AH recruited, consented and managed the patients.

$\mathrm{AH}, \mathrm{KLW}$ and PAS wrote the manuscript.

All authors read and approved the manuscript.

\section{References}

[1] Johnston, D.F., Sondekoppam, R.V., Uppal, V., Litchfield, R., Griffin, R. and Ganapathy, S. (2020) Effect of Combining Peri-Hamstring Injection or Anterior Obturator Nerve Block on the Analgesic Efficacy of Adductor Canal Block for Anterior Cruciate Ligament Reconstruction: A Randomized Controlled Trial. BJA, 124, 299-307. https://doi.org/10.1016/j.bja.2019.11.032

[2] Abdallah, F.W., Brull, R., Joshi, G.P. and Society for Ambulatory Anesthesia (SAMBA) (2019) Pain Management for Ambulatory Arthroscopic Anterior Cruciate Ligament Reconstruction: Evidence-Based Recommendations from the Society for Ambulatory Anesthesia. Anesthesia \& Analgesia, 128, 631-640. https://doi.org/10.1213/ANE.0000000000003976

[3] Sinha, S. (2019) How I Do It: Infiltration between Popliteal Artery and Capsule of Knee (iPACK). https://www.asra.com/asra-news/article/158/how-i-do-it-infiltrationbetween-poplite

[4] Mulroy, M.F., Larkin, K.L., Batra, M.S., Hodgson, P.S. and Owens, B.D. (2001) Femoral Nerve Block with $0.25 \%$ or $0.5 \%$ Bupivacaine Improves Postoperative Analgesia Following Outpatient Arthroscopic Anterior Cruciate Ligament Repair. Regional Anesthesia and Pain Medicine, 26, 24-29. 
https://doi.org/10.1053/rapm.2001.20773

[5] Thobhani, S., Scalercio, L., Elliott, C.E., Nossaman, B.D., Thomas, L.C., Yuratich, D., et al. (2018) Novel Regional Techniques for Total Knee Arthroplasty Promote Reduced Hospital Length of Stay: An Analysis of 106 Patients. The Ochsner Journal, 17, 233-238.

[6] Reddy, A.V.G., Jangale, A., Reddy, R.C., Sagi, M., Gaikwad, A. and Reddy, A. (2017) To Compare Effect of Combined Block of Adductor Canal Block (ACB) with IPACK (Interspace between the Popliteal Artery and the Capsule of the Posterior Knee) and Adductor Canal Block (ACB) Alone on Total Knee Replacement in Immediate Postoperative Rehabilitation. International Journal of Orthopaedics Sciences, 3, 141-145. https://doi.org/10.22271/ortho.2017.v3.i2c.21

[7] Tran, J., Peng, P.W.H., Gofeld, M., et al. (2019) Anatomical Study of the Innervation of Posterior Knee Joint Capsule: Implication for Image-Guided Intervention. Regional Anesthesia \& Pain Medicine, 44, 234-238.

https://doi.org/10.1136/rapm-2018-000015

[8] Runge, C., Moriggl, B., Børglum, J., et al. (2017) The Spread of Ultrasound-Guided Injectate from the Adductor Canal to the Genicular Branch of the Posterior Obturator Nerve and the Popliteal Plexus: A Cadaveric Study. Regional Anesthesia \& Pain Medicine, 42, 725-730. https://doi.org/10.1097/AAP.0000000000000675

[9] Kampitak, W., Tansatit, T., Tanavalee, A. and Ngarmukos, S. (2019) Optimal Location of Local Anesthetic Injection in the Interspace between the Popliteal Artery and Posterior Capsule of the Knee (iPACK) for Posterior Knee Pain after Total Knee Arthroplasty: An Anatomical and Clinical Study. Korean Journal of Anesthesiology, 72, 486-494. https://doi.org/10.4097/kja.19060

[10] Niesen, A.D., Harris, D.J., Johnson, C.S., et al. (2018) Interspace between Popliteal Artery and Posterior Capsule of the Knee (IPACK) Injectate Spread: A Cadaver Study. Journal of Ultrasound in Medicine, 38, 741-745. https://doi.org/10.1002/jum.14761

[11] Elliott, C.E., Myers, T.J., Soberon, J.R., et al. (2015) The Adductor Canal Block Combined with iPACK Improves Physical Therapy Performance and Reduces Hospital Length of Stay (Abstract 197). 40th Annual Regional Anesthesiology and Acute Pain Medicine Meeting, Las Vegas, 14-16 May 2015.

[12] (2012) Practice Guidelines for Acute Pain Management in the Perioperative Setting: An Updated Report by the American Society of Anesthesiologists Task Force on Acute Pain Management. Anesthesiology, 116, 248-273.

https://doi.org/10.1097/ALN.0b013e31823c1030

[13] Williams, B.A., Kentor, M.L., Vogt, M.T., et al. (2004) Economics of Nerve Block Pain Management after Anterior Cruciate Ligament Reconstruction: Potential Hospital Cost Savings via Associated Postanesthesia Care Unit Bypass and Same-Day Discharge. Anesthesiology, 100, 697-706. https://doi.org/10.1097/00000542-200403000-00034

[14] Hebl, J.R., Dilger, J.A., Byer, D.E., et al. (2008) A Pre-Emptive Multimodal Pathway Featuring Peripheral Nerve Block Improves Perioperative Outcomes after Major Orthopedic Surgery. Regional Anesthesia \& Pain Medicine, 33, 510-517. https://doi.org/10.1097/00115550-200811000-00002

[15] Mahoney, O.M., Noble, P.C., Davidson, J., et al. (1990) The Effect of Continuous Epidural Analgesia on Postoperative Pain, Rehabilitation, and Duration of Hospitalization in Total Knee Arthroplasty. Clinical Orthopaedics and Related Research, 260, 30-37. https://doi.org/10.1097/00003086-199011000-00007 
[16] Tharwat, A.I. (2011) Combined Posterior Lumbar Plexus-Sciatic Nerve Block versus Combined Femoral-Obturator-Sciatic Nerve Block for ACL Reconstruction. Local and Regional Anesthesia, 4, 1-6. https://doi.org/10.2147/LRA.S15635

[17] O’Leary, S.T., Unwin, A., Smith, B.L. and Allum, R.L. (2000) The "3 in 1" Lumbar Plexus Block Following Anterior Cruciate Ligament Reconstruction with Autologous Hamstring Tendons. Knee, 7, 95-99. https://doi.org/10.1016/S0968-0160(00)00033-8

[18] Jankowski, C.J., Hebl, J.R., Stuart, M.J., Rock, M.G., Pagnano, M.W. and Beighley, C.M., Schroeder, D.R. and Horlocker, T.T. (2003) A Comparison of Psoas Compartment Block and Spinal and General Anesthesia for Outpatient Knee Arthroscopy. Anesthesia \& Analgesia, 97, 1003-1009. https://doi.org/10.1213/01.ANE.0000081798.89853.E7

[19] Vorobeichik, L., Brull, R., Joshi, G.P. and Abdallah, F.W. (2019) Evidence Basis for Regional Anesthesia in Ambulatory Anterior Cruciate Ligament Reconstruction: Part I-Femoral Nerve Block. Anesthesia \& Analgesia, 128, 58-65. https://doi.org/10.1213/ANE.0000000000002854

[20] Sehmbi, H., Brull, R., Shah, U.J., et al. (2019) Evidence Basis for Regional Anesthesia in Ambulatory Arthroscopic Knee Surgery and Anterior Cruciate Ligament Reconstruction: Part II: Adductor Canal Nerve Block-A Systematic Review and Meta-Analysis. Anesthesia \& Analgesia, 128, 223-238. https://doi.org/10.1213/ANE.0000000000002570

[21] Jansen, T.K., Miller, B.E., Arretche, N. and Pellegrini, J.E. (2009) Will the Addition of a Sciatic Nerve Block to a Femoral Nerve Block Provide Better Pain Control Following Anterior Cruciate Ligament Repair Surgery? AANA Journal, 77, 213-218.

[22] Sinha, S.K., Abrams, J.H., Arumugam, S., et al. (2012) Femoral Nerve Block with Selective Tibial Nerve Block Provides Effective Analgesia without Foot Drop after Total Knee Arthroplasty: A Prospective, Randomized, Observer-Blinded Study. Anesthesia \& Analgesia, 115, 202-206. https://doi.org/10.1213/ANE.0b013e3182536193

[23] Sakura, S., Hara, K., Ota, J. and Tadenuma, S. (2010) Ultrasound-Guided Peripheral Nerve Blocks for Anterior Cruciate Ligament Reconstruction: Effect of Obturator Nerve Block during and after Surgery. Journal of Anesthesia, 24, 411-417. https://doi.org/10.1007/s00540-010-0916-3

[24] Yung, E.M., Brull, R., Albrecht, E., Joshi, G.P. and Abdallah, F.W. (2019) Evidence Basis for Regional Anesthesia in Ambulatory Anterior Cruciate Ligament Reconstruction: Part III: Local Instillation Analgesia-A Systematic Review and $\mathrm{Me}-$ ta-Analysis. Anesthesia \& Analgesia, 128, 426-437. https://doi.org/10.1213/ANE.0000000000002599

[25] Runge, C., Bjørn, S., Jensen, J.M., Nielsen, N.D., Vase, M., Holm, C. and Bendtsen, T.F. (2018) The Analgesic Effect of a Popliteal Plexus Blockade after Total Knee Arthroplasty: A Feasibility Study. Acta Anaesthesiologica Scandinavica, 62, 1127-1132. https://doi.org/10.1111/aas.13145

[26] Kerr, D.R. and Kohan, L. (2008) Local Infiltration Analgesia: A Technique for the Control of Acute Postoperative Pain Following Knee and Hip Surgery: A Case Study of 325 Patients. Acta Orthopaedica, 79, 174-183. https://doi.org/10.1080/17453670710014950

[27] Ohgoshi, Y., Matsutani, M. and Kubo, E.N. (2019) Use of IPACK Block with Continuous Femoral Triangle Block for Total Knee Arthroplasty: A Clinical Experience. Journal of Clinical Anesthesia, 54, 52-54.

https://doi.org/10.1016/j.jclinane.2018.10.045 


\section{List of Abbreviations}

IPACK: Interspace between the Popliteal Artery and Capsule of the Knee ACLR: Anterior Cruciate Ligament Reconstruction

PNB: Peripheral Nerve Block

FNB: Femoral Nerve Block

ASA: American Society of Anaesthesia

BMI: Body Mass Index

GA: General Anaesthesia

LMA: Laryngeal Mask Airway

PACU: Post Anaesthesia Care Unit 